\title{
Simplified expressions for calculating Debye temperature and melting point of II-VI and III-V semiconductors
}

\author{
Salah Daoud \\ Laboratoire Matériaux Et Systèmes Electroniques (LMSE), Université De Bordj Bou Arreridj, 34000, Algérie \\ E-mail: salah_daoud07@yahoo.fr
}

Copyright () 2015 Salah Daoud. This is an open access article distributed under the Creative Commons Attribution License, which permits unrestricted use, distribution, and reproduction in any medium, provided the original work is properly cited.

\begin{abstract}
Simple empirical expressions between the Debye temperature and the bond length and also between the melting point and the bond length have been proposed. These formulas have been established for two groups of $\mathrm{A}^{\mathrm{N}} \mathrm{B}^{8-\mathrm{N}}$ type binary semiconductors (groups: II-VI and III-V). A good correlation between the Debye temperature and the bond length and also between the melting point and the bond length is obtained. The minimum average percentage deviations in the present approach reveal that our model proves its identity and soundness compared to those of other author relations.
\end{abstract}

Keywords: Debye Temperature; Melting Point; $A^{I I}-B^{V I}$ and $A^{I I I}-B^{V}$ Binary Compounds; Bond Length.

\section{Introduction}

The Debye temperature $\theta_{\mathrm{D}}$ of material is a suitable thermodynamic quantity to describe several phenomena of solidstate physics which are associated with lattice vibrations [1]. It is naturally depends on several other quantities, such as the pressure, elastic constants, and other thermal quantities, such as specific heat and lattice thermal conductivity [2]. At ambient temperature and pressure, several II-VI and III-V binary semiconductors possess the cubic zincblende structure; these binary compounds have potential applications in the fields of electronic and optoelectronic devices [3]. The development of new optoelectronic materials depends mostly on the materials engineering at a practical level, and also on a good understanding of the properties of materials [4]. Knowledge of different thermodynamic properties such as Debye temperature helps engineers in the improvement of the manufacturing of the semiconductor devices by good selecting of the appropriate materials [2].

And due to technological importance of II-VI and III-V semiconductors, several experimental and theoretical works [49] on their electronic, optical, mechanical and thermal properties were published.

The present work aims to establish simple empirical expressions between the Debye temperature and the bond length, and between the melting point and the bond length for II-VI and III-V semiconductors.

\section{Theory, results and discussion}

\subsection{Debye temperature}

Based on the previous works of Kumar et al. [2, 9] on $\mathrm{A}^{\mathrm{I}} \mathrm{B}^{\mathrm{III}} \mathrm{C}_{2}{ }^{\mathrm{VI}}$ and $\mathrm{A}^{\mathrm{II}} \mathrm{B}^{\mathrm{IV}} \mathrm{C}_{2}{ }^{\mathrm{V}}$ ternary chalcopyrite semiconductors, and on $\mathrm{A}^{\mathrm{II}} \mathrm{B}^{\mathrm{VI}}$ and $\mathrm{A}^{\mathrm{III}} \mathrm{B}^{\mathrm{V}}$ binary semiconductor compounds, the Debye temperature and some other physical quantities are related by [2], [9].

$\theta_{\mathrm{D}}=\mathrm{K}_{1}\left[(\mathrm{M})^{-1 / 2}(\mathrm{~V})^{1 / 6}\left(\hbar \omega_{\mathrm{p}}\right)^{1.1666}\right]-\mathrm{K}_{2}$

Where, $\mathrm{K}_{1}$ and $\mathrm{K}_{2}$ are two empirical parameters, slightly depend on the nature group of material, $\mathrm{M}$ is the mean atomic weight, $\left(\hbar \omega_{\mathrm{p}}\right)$ is Plasmon energy, and V is the mean atomic volume. 
Our principal idea is to write the Debye temperature $\theta_{\mathrm{D}}$ as functional of the bond length $\mathrm{d}$; the bond length $\mathrm{d}$ in angstroms and the Plasmon energy $\left(\hbar \omega_{\mathrm{p}}\right)$ in $\mathrm{eV}$ can be related by the following formula [10].

$\mathrm{d}=\mathrm{C}_{1}\left(\hbar \omega_{\mathrm{p}}\right)^{-2 / 3}$

Where, $\mathrm{C}_{1}$ is constant, which depends on the nature group of material. The relevant value of the constant $\mathrm{C}_{1}$ for some binary compounds is: 15.30 [10].

Reciprocally to the formula of Eq. (2), the Plasmon energy ( $\left.\hbar \omega_{\mathrm{p}}\right)$ can be written approximately as function of bond length $\mathrm{d}$ by the following expression:

$\left(\hbar \omega_{\mathrm{p}}\right)=\mathrm{C}_{2} \mathrm{~d}^{-3 / 2}$

Where, $\mathrm{C}_{2}$ is constant.

In other hand, for cubic zincblende crystals, the mean atomic volume $\mathrm{V}$ and the lattice parameter a are related by:

$\mathrm{V}=\mathrm{a}^{3} / 8$

And the bond length $\mathrm{d}$ and the lattice parameter a are related by [4]

$a=(4 / \sqrt{3}) d$

So the mean atomic volume $\mathrm{V}$ can be written as function of bond length $\mathrm{d}$ by the following expression:

$V=a^{3} / 8=(8 / 3 \sqrt{3}) d^{3}$

$\mathrm{V}=\mathrm{C}_{3} \mathrm{~d}^{3}$

For object to simplify the unity of the quantity $\left[(\mathrm{M})^{-1 / 2}(\mathrm{~V}){ }^{1 / 6}\left(\hbar \omega_{\mathrm{p}}\right)^{1.1666}\right]$ in the formula of Eq. (1), it's important to write the value: $1.1666=7 / 6$.

Replaced in the expression of Eq. (1), the Plasmon energy ( $\left(\omega_{\mathrm{p}}\right)$ with its expression (Eq. (3)), and the mean atomic volume $\mathrm{V}$ with its expression (Eq. (6-b)), we obtain the following formula:

$\theta_{\mathrm{D}}=\mathrm{K}_{3}\left[1 /\left(\mathrm{M}^{1 / 2} \mathrm{~d}^{5 / 4}\right)\right]-\mathrm{K}_{4}$

Where, $\mathrm{K}_{3}$ and $\mathrm{K}_{4}$ are two empirical parameters, slightly depend on the nature group of material.

So a linear regression between the Debye temperature $\theta_{D}$ and the quantity $\left[1 /\left(\mathrm{M}^{1 / 2} \mathrm{~d}^{5 / 4}\right)\right]$ has been established.

The values of the mean atomic weight, the experimental lattice parameter a, the bond length $\mathrm{d}$, and the quantity $\left[1 /\left(\mathrm{M}^{1 / 2}\right.\right.$ $\mathrm{d}^{5 / 4}$ )] (in $10^{12} \mathrm{Kg}^{-1 / 2} \mathrm{~m}^{-5 / 4}$ ) of III-V and II-VI compounds are listed in Table 1 .

Table 1: Mean Atomic Weight M, Experimental Lattice Parameter $a$, Bond Length d, and the Quantity [1/ $\left.\left(\mathrm{M}^{1 / 2} \mathrm{~d}^{5 / 4}\right)\right]$ of III-V and II-VI Compounds

\begin{tabular}{|c|c|c|c|c|c|}
\hline Group & Compounds & $\mathrm{M}\left(10^{-3} \mathrm{~kg}\right)$ & $\mathrm{a}\left(10^{-10} \mathrm{~m}\right)[4]$ & $\mathrm{d}\left(10^{-10} \mathrm{~m}\right)$ & $1 /\left(\mathrm{M}^{1 / 2} \mathrm{~d}^{5 / 4}\right)\left(10^{12} \mathrm{Kg}^{-1 / 2} \mathrm{~m}^{-5 / 4}\right)$ \\
\hline \multirow{15}{*}{ III-V } & $\mathrm{BN}$ & 20.87 & 4.5383 & 1.965 & 9.408 \\
\hline & $\mathrm{BP}$ & 42.87 & 4.777 & 2.069 & 6.157 \\
\hline & AlP & 28.98 & 5.4635 & 2.366 & 6.331 \\
\hline & AlAs & 50.95 & 5.66139 & 2.451 & 4.567 \\
\hline & $\mathrm{AlSb}$ & 74.37 & 6.1355 & 2.657 & 3.419 \\
\hline & $\mathrm{GaP}$ & 50.35 & 5.4508 & 2.360 & 4.817 \\
\hline & GaAs & 72.32 & 5.6533 & 2.448 & 3.840 \\
\hline & $\mathrm{GaSb}$ & 95.74 & 6.09593 & 2.640 & 3.038 \\
\hline & InP & 72.9 & 5.869 & 2.541 & 3.650 \\
\hline & InAs & 94.87 & 6.0583 & 2.623 & 3.075 \\
\hline & $\mathrm{InSb}$ & 118.29 & 6.47937 & 2.806 & 2.532 \\
\hline & $\mathrm{BeS}$ & 20.54 & 4.865 & 2.107 & 8.694 \\
\hline & $\mathrm{BeSe}$ & 43.88 & 5.137 & 2.224 & 5.557 \\
\hline & $\mathrm{BeTe}$ & 68.31 & 5.617 & 2.432 & 3.983 \\
\hline & $\mathrm{ZnS}$ & 48.72 & 5.4102 & 2.343 & 4.943 \\
\hline \multirow{5}{*}{ II-VI } & $\mathrm{ZnSe}$ & 72.17 & 5.6692 & 2.455 & 3.831 \\
\hline & $\mathrm{ZnTe}$ & 96.5 & 6.009 & 2.602 & 3.080 \\
\hline & $\mathrm{CdS}$ & 72.23 & 5.825 & 2.522 & 3.702 \\
\hline & $\mathrm{CdSe}$ & 95.68 & 6.077 & 2.631 & 3.050 \\
\hline & $\mathrm{CdTe}$ & 120 & 6.481 & 2.806 & 2.513 \\
\hline
\end{tabular}


Figure 1 show the variation of Debye temperature as function of the quantity $\left[1 /\left(\mathrm{M}^{1 / 2} \mathrm{~d}^{5 / 4}\right)\right]$ of III-V and II-VI materials. The empirical parameters obtained for III-V compounds are: $K_{3}=112.66\left(10^{-12} \mathrm{Kg}^{1 / 2} \mathrm{~m}^{5 / 4} \mathrm{~K}\right)$ and $\mathrm{K}_{4}=90.74 \mathrm{~K}$ respectively, and for II-VI compounds are: $\mathrm{K}_{3}=106.99\left(10^{-12} \mathrm{Kg}^{1 / 2} \mathrm{~m}^{5 / 4} \mathrm{~K}\right)$ and $\mathrm{K}_{4}=92.09 \mathrm{~K}$ respectively.

Our calculated and known values of Debye temperature $\theta_{\mathrm{D}}$ of III-V and II-VI compounds are presented in Table 2.

In the case of III-V materials, the average percentage deviation is calculated and to be found improved in comparison with other result (3.34 \%) cited Kumar et al [2], it is only about $2.42 \%$.

Eq. (7) is used to predict the Debye temperature of BSb material. The experimental lattice parameter of this compound in its zincblende phase is equal to: $\mathrm{a}=5.16 \AA$ [11], so the experimental bend length $\mathrm{d}$ of BSb compound in its zincblende phase is equal to: $2.2344 \AA$. The result obtained of the quantity [1/( $\left.\mathrm{M}^{1 / 2} \mathrm{~d}^{5 / 4}\right)$ ] is equal to: $4.496\left(10^{12} \mathrm{Kg}^{-1 / 2}\right.$ $\left.\mathrm{m}^{-5 / 4}\right)$; the predicted value of the Debye temperature of BSb material is equal to $415.81 \mathrm{~K}$; this value is in general in agreement with the value $456.07 \mathrm{~K}$ obtained in our previous work [6]. The deviation between our value and this cited in the Ref. [6] is about $8.83 \%$.
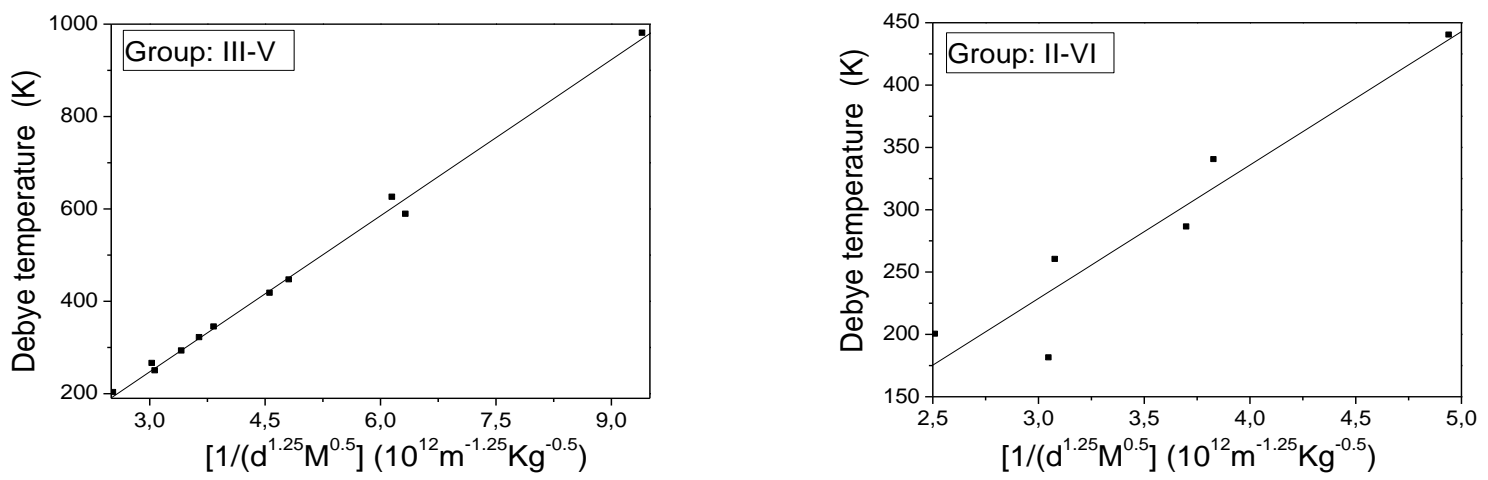

Fig. 1: Plot between Debye Temperature and the Quantity $\left[1 /\left(\mathrm{M}^{1 / 2} \mathrm{D}^{5 / 4}\right)\right]$ Of III-V and II-VI Compounds.

In the case of II-VI materials, the average percentage deviation is also calculated and to be also found improved in comparison with other result $(14.01 \%)$ cited by Kumar et al [2], it is about $10.54 \%$.

Table 2: Debye Temperature $\Theta_{\mathrm{d}}$ of III-V and II-VI Compounds. Experimental Values of Debye Temperature $\Theta_{\mathrm{d}}$ with * Are Taken From the Ref [4] and References Therein).

\begin{tabular}{cllll}
\hline Group & Compounds & Experimental Values, cited in Ref [2] & Present Work Eq.(7) & Percentage deviation (\%) \\
\hline & BN & 980 & 969.16 & 1.11 \\
BP & 625 & 602.88 & 3.54 \\
& AlP & 588 & 622.53 & 5.87 \\
AlAs & 417 & 423.80 & 1.63 \\
& AlSb & 292 & 294.41 & 0.83 \\
& GaP & 446 & 451.97 & 1.34 \\
& GaAs & 344 & 341.91 & 0.61 \\
III-V & GaSb & 265 & 251.47 & 5.10 \\
& InP & 321 & 320.48 & 0.16 \\
& InAs & 249 & 255.71 & 2.69 \\
& InSb & 202 & 194.53 & 3.70 \\
& Average percentage deviation & & $2.42 \%$ \\
BeS & - & 838.08 & - \\
BeSe & - & 502.47 & - \\
BeTe & - & 334.09 & - \\
ZnS & $440^{*}$ & 436.78 & 0.73 \\
ZnSe & $340^{*}$ & 317.77 & 6.54 \\
ZnTe & $260^{*}$ & 237.48 & 8.66 \\
CdS & 286 & 303.95 & 6.28 \\
CdSe & 181 & 234.27 & 29.43 \\
CdTe & 200 & 176.80 & 11.60 \\
Average percentage deviation & & $10.54 \%$ \\
\hline
\end{tabular}

Unfortunately as far as we know, there is no experimental data available in the literature on the Debye temperature of beryllium chalcogenide (BeS, BeSe and BeTe) compounds. 


\subsection{Melting point}

The Debye temperature $\theta_{\mathrm{D}}$ and the melting point $\mathrm{T}_{\mathrm{m}}$ of some cubic zincblende crystals are related by [2].

$\theta_{\mathrm{D}}=-\mathrm{K}_{5}+\mathrm{K}_{6} \mathrm{~T}_{\mathrm{m}}$

Where, $\mathrm{K}_{5}$ and $\mathrm{K}_{6}$ are two empirical parameters, slightly depend on the nature group of material.

Reciprocally to the formula of Eq. (8), the melting point $\mathrm{T}_{\mathrm{m}}$ can be written approximately as function of Debye temperature $\theta_{\mathrm{D}}$ by the following expression:

$\mathrm{T}_{\mathrm{m}}=\mathrm{K}_{7} \theta_{\mathrm{D}}+\mathrm{K}_{8}$

Where, $\mathrm{K}_{7}$ and $\mathrm{K}_{8}$ are two constants

Replacing the Debye temperature $\theta_{\mathrm{D}}$ in the expression of Eq. (9), with its expression of Eq. (7), we obtain the following formula:

$$
\mathrm{T}_{\mathrm{m}}=\mathrm{K}_{9}\left[1 /\left(\mathrm{M}^{1 / 2} \mathrm{~d}^{5 / 4}\right)\right]+\mathrm{K}_{10}
$$

Where, $\mathrm{K}_{9}$ and $\mathrm{K}_{10}$ are two empirical parameters, slightly depend on the nature group of material.

Figure 2 show the variation of the melting point $T_{m}$ as function of the quantity $\left[1 /\left(\mathrm{M}^{1 / 2} \mathrm{~d}^{5 / 4}\right)\right]$ of III-V and II-VI materials.
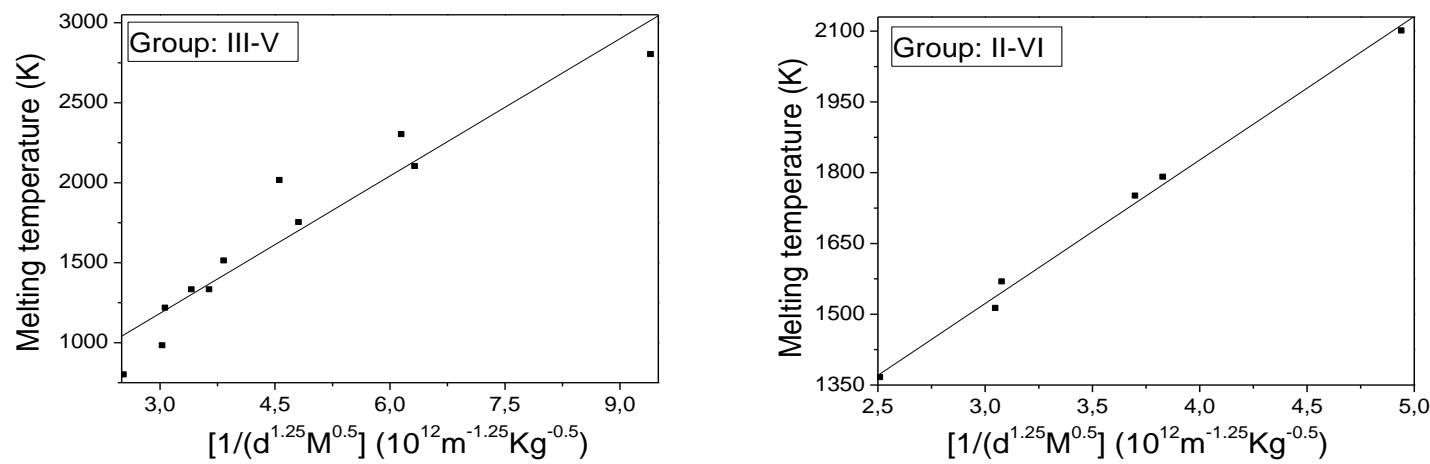

Fig. 2: Plot between Melting Point $\mathrm{T}_{\mathrm{m}}$ and the Quantity $\left[1 /\left(\mathrm{M}^{1 / 2} \mathrm{D}^{5 / 4}\right)\right]$ of III-V and II-VI Materials.

The empirical parameters obtained for III-V compounds are: $\mathrm{K}_{9}=286.21\left(10^{-12} \mathrm{Kg}^{1 / 2} \mathrm{~m}^{5 / 4} \mathrm{~K}\right)$, and $\mathrm{K}_{10}=325.17 \mathrm{~K}$ respectively, and those obtained for II-VI type compounds are: $\mathrm{K}_{9}=304.24\left(10^{-12} \mathrm{Kg}^{1 / 2} \mathrm{~m}^{5 / 4} \mathrm{~K}\right)$, and $\mathrm{K}_{10}=609.93 \mathrm{~K}$ respectively.

The present calculated and known values of melting point $\mathrm{T}_{\mathrm{m}}$ of III-V and II-VI compounds are presented in Table 3. Unfortunately as far as we know, there is no experimental data available in the literature on the melting point of beryllium chalcogenide (BeS, BeSe and BeTe) compounds.

In the case of III-V materials, the average percentage deviation is calculated and to be found improved in comparison with other results (from $9.99 \%$ to $10.45 \%$ ) cited Kumar et al [2], it is about $9.57 \%$; and in the case of II-VI materials, the average percentage deviation is also calculated and also to be found improved in comparison with other results (from $2.37 \%$ to $3.11 \%$ ) cited Kumar et al [2], it is only about $1.0 \%$.

Eq. (9) is used to predict the meting point of $\mathrm{BeS}$ material. The experimental lattice parameter of this compound in its zincblende phase is equal to: $\mathrm{a}=4.865 \AA$ [4], so the experimental bend length $\mathrm{d}$ of BeS compound in its zincblende phase is equal to: $2.107 \AA$. The result obtained of the quantity [1/ $\left.\left(\mathrm{M}^{1 / 2} \mathrm{~d}^{5 / 4}\right)\right]$ is equal to: $8.694\left(10^{12} \mathrm{Kg}^{-1 / 2} \mathrm{~m}^{-5 / 4}\right) ;$ the predicted value of the melting point of $\mathrm{BeS}$ material is equal to $3255 \mathrm{~K}$; this value is very higher than the value $2293 \mathrm{~K}$ cited in the previous work of Verma et al. [12].

\section{Conclusion}

A simple model has been established for calculating the Debye temperature and the melting point of II-VI and III-V semiconductors. The average percentage deviations were estimated for different materials. The maximum average deviation of $10.54 \%$ was obtained in the case of II-VI compounds, and about $2.42 \%$ in the case of III-V materials for the Debye temperature. For melting point, the maximum average deviation of $9.57 \%$ was obtained in the case of III-V compounds, and exactly $1 \%$ in the case of II-VI materials respectively. So the correlation between the Debye temperature $\theta_{\mathrm{D}}$ and the quantity $\left[1 /\left(\mathrm{M}^{1 / 2} \mathrm{~d}^{5 / 4}\right)\right]$, and also between the melting point and the quantity $\left[1 /\left(\mathrm{M}^{1 / 2} \mathrm{~d}^{5 / 4}\right)\right]$ gives a good agreement with the experimental values. 
Table 3: Melting Point $T_{m}$ and Percentage Deviation of III-V and II-VI Compounds Using a Linear Fit.

\begin{tabular}{lllll}
\hline Group & Compounds & Experimental Values, cited in Ref [2] & Present Work Eq.(10) & Percentage deviation (\%) \\
\hline & BN & 2800 & 3017.83 & 7.78 \\
& BP & 2300 & 2087.30 & 9.25 \\
& AlP & 2100 & 2137.22 & 1.77 \\
& AlAs & 2013 & 1632.34 & 18.91 \\
& AlSb & 1330 & 1303.64 & 1.98 \\
& GaP & 1750 & 1703.92 & 2.63 \\
& GaAs & 1510 & 1424.31 & 5.67 \\
III-V & GaSb & 980 & 1194.56 & 21.89 \\
& InP & 1330 & 1369.87 & 3.00 \\
& InAs & 1215 & 1205.32 & 0.80 \\
& InSb & 798 & 1049.89 & 31.56 \\
& Average percentage deviation & & $9.57 \%$ \\
& BeS & - & 3255.00 & - \\
& BeSe & - & 2300.64 & - \\
& BeTe & - & 1821.83 & 0.66 \\
& ZnS & 2100 & 2113.83 & 0.81 \\
& ZnSe & 1790 & 1775.42 & 1.33 \\
ZnTe & 1568 & 1547.11 & 0.79 \\
CdS & 1750 & 1736.12 & 1.72 \\
& CdSe & 1512 & 1537.97 & 0.70 \\
CdTe & 1365 & 1374.55 & $1.00 \%$ \\
Average percentage deviation & & & \\
\hline
\end{tabular}

\section{References}

[1] H. Siethoff, "Debye temperature, self-diffusion and elastic constants of intermetallic compounds", Intermetallics, Vol. 5, No. 8, (1997), pp. 625-632. http://www.sciencedirect.com/science/article/pii/S096697959700037X. http://dx.doi.org/10.1016/S0966-9795(97)00037-X.

[2] V. Kumar, V. Jha \& A. K. Shrivastava, "Debye temperature and melting point of II-VI and III-V semiconductors", Crystal Research and Technology, Vol. 45, No. 9, (2010), pp. 920-924. http://www. onlinelibrary.wiley.com/doi/10.1002/crat.201000268/pdf. http://dx.doi.org/10.1002/crat.201000268.

[3] A. Bahadur \& M. Mishra, "Correlation between refractive index and electronegativity difference for $\mathrm{A}^{\mathrm{N}} \mathrm{B}^{8 \mathrm{~N}}$ type binary semiconductors", Acta Physica Polonica A, Vol. 123, No. 4, (2013), pp. 737-740. http://przyrbwn.icm.edu.p1/APP/PDF/123/a123z4p18.pdf. http://dx.doi.org/10.12693/APhysPolA.123.737.

[4] S. Adachi, "Properties of Group-IV, III-V and II-VI Semiconductors", John Wiley \& Sons, England, (2005). Print ISBN: 9780470090329. Online ISBN: 9780470090343. http://dx.doi.org/10.1002/0470090340.

[5] A. S. Verma, B. K. Sarkar \& V. K. Jindal "Inherent properties of binary tetrahedral semiconductors", Physica B, Vol. 405, (2010), pp. 17371739. http://www.sciencedirect.com/science/article/pii/S0921452610000396. http://dx.doi.org/10.1016/j.physb.2010.01.029.

[6] S. Daoud, "Sound velocities and thermal properties of BX (X=As, Sb) compounds", International journal of scientific world, Vol. 3, No. 1, (2015), pp. 43-48. http://www.sciencepubco.com/index.php/IJSW/article/view/4039. http://dx.doi.org/10.14419/ijsw.v3i1.4039.

[7] S. Daoud, N. Bioud, N. Lebgaa \& R. Mezouar "Optoelectronic and thermal properties of boron- bismuth compound", International Journal of Physical Research", Vol. 2, No. 2, (2014), pp. 27-31. http://www.sciencepubco.com/index.php/IJPR/article/view/2760. http://dx.doi.org/10.14419/ijpr.v2i2.2760.

[8] M. Ustundag, M. Aslan, \& Battal G. Yalcin, "The first-principles study on physical properties and phase stability of Boron-V (BN, BP, BAs, BSb and BBi) compounds", Computational Materials Science, Vol. 81, (2014) pp. 471- 477.

[9] V. Kumar, A. K. Shrivastava, R. Banerji, \& D. Dhirhe, "Debye temperature and melting point of ternary chalcopyrite semiconductors", Solid State Communications, Vol. 146, No. 25-26, (2009), pp. 1008-1011. http://www.sciencedirect.com/science/article/pii/S0038109809002026. http://dx.doi.org/10.1016/j.ssc.2009.04.003.

[10] S. K. Gorai \& P. Mahto, "Plasmon energy and lattice energy of binary tetrahedral semiconductors and I-VII ionic compounds", Indian Journal of Physics, Vol.86, No.4, (2012), pp. 273-277. http://www.link.springer.com/content/pdf/10.1007\%2Fs12648-012-0053-y.pdf. http://dx.doi.org/10.1007/s12648-012-0053-y.

[11] E. V. Clougherty \& L. Kaufman, "Thermodynamic study of synthesis of new compound phases under high pressure", Scientific Report N.1, Cambridge, Massachusetts, 1967. www.dtic.mil/cgi-bin/GetTRDoc?AD=AD0670561.

[12] A. S. Verma, R. K. Singh \& S. K. RathiV, "Thermal property of binary tetrahedral semiconductors", Physica B, Vol. 404, No. 21, (2009), pp. 4051-4053. http://www.sciencedirect.com/science/article/pii/S0921452609006681. http://dx.doi.org/10.1016/j.physb.2009.07.157. 